\title{
Maxime Prévost, Rictus romantiques : politiques du rire chez Victor Hugo
}

Judith Wulf

\section{(2) OpenEdition}

1 Journals

\section{Édition électronique}

URL : https://journals.openedition.org/studifrancesi/40951

DOI : 10.4000/studifrancesi.40951

ISSN : 2421-5856

Éditeur

Rosenberg \& Sellier

\section{Édition imprimée}

Date de publication : 1 juillet 2004

Pagination : 210-211

ISSN : 0039-2944

\section{Référence électronique}

Judith Wulf, "Maxime Prévost, Rictus romantiques : politiques du rire chez Victor Hugo », Studi Francesi

[En ligne], 142 (XLVIII | I) | 2004, mis en ligne le 30 novembre 2015, consulté le 09 septembre 2021.

URL : http://journals.openedition.org/studifrancesi/40951 ; DOI : https://doi.org/10.4000/

studifrancesi.40951

Ce document a été généré automatiquement le 9 septembre 2021.

\section{(c)}

Studi Francesi è distribuita con Licenza Creative Commons Attribuzione - Non commerciale - Non opere derivate 4.0 Internazionale. 


\title{
Maxime Prévost, Rictus romantiques: politiques du rire chez Victor Hugo
}

\author{
Judith Wulf
}

\section{RÉFÉRENCE}

MAXIME PRÉVOST, Rictus romantiques : politiques du rire chez Victor Hugo, Presses de l'Université de Montréal, 2002, pp. 373

1 Présenté à l'origine comme thèse de doctorat (2000) sous le titre Gaieté perverse et rire de force dans l'œuvre de Victor Hugo, l'ouvrage de Maxime Prévost s'appuie plus particulièrement sur trois romans «historico-gothiques», Han d'Islande, Notre-Dame de Paris et L'Homme qui rit (1823, 1831 et 1869), sur une pièce, Le Roi s'amuse (1832), sur une «sorte de croisement entre l'histoire et le reportage», Choses vues, sur un pamphlet, Napoléon le Petit (1852), sur un mémoire historique, Histoire d'un crime (1877), sur un roman social, Les Misérables (1862), sur un ouvrage critique, William Shakespeare (1864) et sur une épopée métaphysique, La Fin de Satan. À partir de l'étude de ce corpus, l'auteur distingue deux types de rictus qui caractériseraient l'œuvre hugolienne, la "gaieté perverse» de l'oppresseur et le rire forcé de sa victime. L'analyse s'inscrit dans une perspective d'histoire de la littérature qui cherche à montrer comment ce type de mise en forme du rire découle de «l'énorme soupçon que le romantisme a fait peser sur la gaieté», mais touche également à l'histoire des idées, soulignant que «l'émergence du rictus romantique coïncide avec celle d'une nouvelle conscience historique».

2 Pour appréhender les manifestations du rire chez Hugo, l'auteur choisit de s'appuyer sur des détails plutôt que sur des «systèmes idéologiques globaux, fussent-ils politiques, esthétiques ou philosophiques», détails qui, une fois reliés, ont vocation à former des figures trouvant elles-mêmes leur place dans des «nébuleuses topiques», notamment par l'entremise du personnel littéraire.

Cherchant à interpréter cette série de topoï dans leur transformation, l'étude s'organise en trois volets selon un plan chronologique. La première section est ainsi consacrée 
plus particulièrement à Han d'Islande (chapitre 1), Notre-Dame de Paris (chapitre 2) et Le Roi s'amuse (chapitre 3) avec le développement de la gaieté perverse et des rieurs méchants qui rient du mal qu'ils infligent.

4 Vient ensuite une période de transition qui mène de la gaieté perverse au rire de force. Travaillant au manuscrit des Misères, l'auteur de Choses Vues s'intéresse plus particulièrement à d'autres rictus de la topique romantique, ceux du forçat, de la prostitué et du gamin de Paris (chapitre 5). Cette tendance se confirme, dans une perspective satirique, avec la rédaction de Napoléon le Petit, d'Histoire d'un crime et des Châtiments comportant les figures du tyran et du soldat (chapitre 4).

5 Avec l'exil, une troisième étape voit un Hugo qui ne se contente plus d'observer l'horreur du passé, mais cherche à expliquer les mécanismes de l'oppression dont il est désormais une victime, raffinement de son analyse sur la gaieté perverse que manifestent La Fin de Satan (chapitre 6), William Shakespeare (chapitre 7) et L'Homme qui rit (chapitre 8).

6 Après avoir souligné l'intérêt de l'établissement d'une «topique historique», Maxime Prévost conclut en insistant sur l'intérêt actuel de l'étude de la littérature du XIXe siècle qui a le pouvoir de «mettre à nu, de manière différentielle, les présupposés de notre époque». L'ouvrage comprend également une bibliographie et un index. 